\title{
Educação a distância e as bibliotecas universitárias: uma interação necessária
}

\author{
Maria Elizabeth de Oliveira Costa
}

Mestre em Tecnologia e Gestão em EAD/UFRPE. Bibliotecária-Documentalista do Sistema de Bibliotecas da UFMG

Marizete Silva Santos

Doutora em Ciência da Computação. Professora da Universidade Federal Rural de Pernambuco. Coordenadora do Programa de Pós-Graduação em Tecnologia e Gestão em Educação a Distância

Anderson Luiz da Rocha Barbosa

Doutor em Física. Professor da Universidade Federal Rural de Pernambuco. Programa de PósGraduação em Tecnologia e Gestão em Educação a Distância

http://dx.doi.org/10.1590/1981-5344/1939

A pesquisa trata do tema Educação a Distância (EAD), Bibliotecas polo e os Recursos Informacionais disponibilizados aos alunos da EAD. Faz uma abordagem sobre EAD, o desenvolvimento dessa modalidade de ensino; sua contribuição social para que chegue aos lugares mais remotos do país. O espaço da pesquisa é a Universidade Federal de Minas Gerais (UFMG), e o foco são as bibliotecas dos polos de apoio presencial da EAD, onde a instituição oferece os cursos de graduação a distância. O objetivo da pesquisa é verificar se as bibliotecas dos polos atendem seus usuários no provimento e acesso às informações científicas necessárias as atividades de ensino, pesquisa e extensão. A pesquisa é de natureza exploratória e de abordagem quali-quantitativa. Este estudo é também caracterizado como pesquisa-ação e seus resultados vêm sendo apresentados à instituição. A pesquisa busca conhecer a visão dos usuários desta modalidade à distância e através do "estudo de usuários" saber a opinião destes. Assim, 
pode-se ter a clareza das necessidades informacionais desses usuários. A investigação contou com um questionário online via software Qualtrics.

Palavras-Chave: Educação à distância (EAD); Bibliotecas Universitárias; Polos de Apoio Presencial; Universidade Federal de Minas Gerais (UFMG).

\section{Distance education and university libraries: a necessary interaction}

The research deals with the theme Distance Education, Libraries and Information Resources available to students of $D L$. It makes an approach to distance education, the development of this type of education and its social contribution to reach the most remote places of the country. The institution researched is the Federal University of Minas Gerais (UFMG), and is the focus are Libraries of $D L$, where the institution offers undergraduate distance education and the focus Access to Information Resources for Educador, sociólogo, etnólogo, poeta, romancista, antropólogo, político users of DL. The purpose of the research and verify that the libraries of the poles serve their students and in providing acess to scientific informations necessary activities of teaching, research and extension. The research is exploratory and qualitative and quantitative approach. The first part of this study is also characterized as action research and its results have been presented to the institution.

Keywords: Distance learning (DL); University Libraries; Polo Support Classroom; Federal University of Minas Gerais (UFMG).

Recebido em 29.07.2014 Aceito em 14.05.2015

\section{Introdução}

A educação de um povo é um dos investimentos mais importantes para o desenvolvimento de uma nação. Darcy Ribeiro (NASCIMENTO, 2001) ${ }^{1}$ já preconizava que as condições para "um ensino com equidade, competência e qualidade [...] era defender a integração com a

\footnotetext{
${ }^{1}$ Educador, sociólogo, etnólogo, poeta, romancista, antropólogo, político.
} 
comunidade, a educação à distância e excelência na formação do magistério." Pode-se concluir com tal afirmação que Darcy tinha a visão de um Brasil para frente, ou seja, o educador anteviu as principais demandas no que se refere às práticas de ensino no país, a preparação dos professores, a educação à distância como solução para quem reside em lugares afastados do perímetro urbano.

O Brasil vem se destacando no campo educacional. De acordo com os dados do Instituto Nacional de Estudos e Pesquisas Educacionais Anísio Teixeira (INEP, 2011), a educação superior está em processo de evolução. O Brasil, juntamente com a Alemanha, Dinamarca, Holanda, Suécia e a Suíça, é o país que mais conseguiu investimentos públicos na área da educação. De acordo com o Censo,

[...] em 2010 o Brasil contava com 6.379.299 matrículas em cursos de graduação, esse total representa mais que o dobro das matrículas de 2001. Apesar do caráter preponderantemente privado da expansão ao longo desse período, tais resultados apontam para certa estabilização da participação desse setor, que, em 2010, atende a 74,2\% das matrículas. Por outro lado, nesse mesmo período, o setor público assiste a uma significativa expansão. As categorias federal e estadual apresentam crescimento no número de matrículas de 2001 a 2010 da ordem de 85,9\% e 66,7\%, respectivamente (BRASIL. Ministério da Educação, 2012).

O uso das tecnologias da informação e da comunicação (TIC) aplicados aos processos da educação tem possibilitado novas oportunidades de ensino às pessoas, permitindo mais informação e consequentemente mais conhecimento. Um país que deseja crescer precisa investir na educação de seu povo, pois ela promove o desenvolvimento social, cultural e econômico. O uso destas tecnologias tem contribuído para o avanço do ensino, principalmente na modalidade de ensino a distância.

A Lei de Diretrizes e Bases da Educação (LDB) (BRASIL, 1996) trouxe um avanço no sistema educacional do Brasil. Aprovada em dezembro de 1996, a LDB visa tornar a escola um espaço de participação social valorizando a democracia, o respeito, a pluralidade cultural e a formação do cidadão.

Desde a aprovação dessa legislação para a educação, o país avançou significadamente neste campo nas últimas décadas, mas ainda há muito para ser feito em relação ao sistema educacional. É reconhecido que há por parte do governo federal interesse em investir para um maior desenvolvimento da educação reduzindo as dificuldades de acesso.

Estamos criando condições para formar engenheiros, médicos, agrônomos, professores, dentistas e técnicos das mais diversas especializações, em municípios dos mais diferentes tamanhos, em todas as regiões (BRASIL, 2011). 
Neste contexto, constata-se que a educação a distância instituída por meio do decreto no 5.622, de 19 de dezembro de 2005, que regulamenta o art. 80 da Lei no 9.394, de 20 de dezembro de 1996, estabelece as diretrizes e bases da educação nacional:

Para os fins deste Decreto, caracteriza-se a educação à distância como modalidade educacional na qual a mediação didático-pedagógica nos processos de ensino e aprendizagem ocorre com a utilização de meios e tecnologias de informação e comunicação [...] (BRASIL, 2007).

Atualmente, pode-se dizer que o país apresenta maiores oportunidades para as pessoas antes excluídas, pois a educação abrange diversas regiões e povoados do país. Então, precisa-se pensar cada vez mais no desenvolvimento e na prática da Educação a Distância (EAD). Segundo Litto (2009), "o Brasil está agora tomando seu devido lugar entre os países que fazem amplo uso da EAD para dar acesso ao conhecimento, e à certificação de competências, a camadas cada vez maiores da população." É um novo país despontado no horizonte. O horizonte das igualdades, das oportunidades, da qualidade de vida, da inclusão social. É a evolução da educação, e consequentemente, da sociedade.

\section{A educação a distância e a Universidade Aberta do Brasil}

A EAD tem contribuído para o avanço na área educacional do país permitindo que o ensino chegue aos lugares mais remotos do país. Diante disso, um novo Brasil está surgindo com novas oportunidades para aqueles que moram nas cidades do interior, e que possuem menos chances de entrar em uma universidade de alguma grande cidade brasileira.

No ano de 2005, o MEC criou a Universidade Aberta do Brasil (UAB) que é definida como um consórcio de instituições federais de educação superior que oferece o ensino a distância e, em parceria com estados e municípios, atua para levá-la ao interior do país. A UAB também conta com o apoio das universidades públicas na formação de professores e com a parceria entre empresas e universidades para formação profissional destes educadores.

Assim, o objetivo principal da UAB é oferecer formação inicial de professores em exercício na educação básica pública, formar novos docentes e propiciar formação continuada, licenciaturas e alguns cursos de graduação para atender regiões carentes.

A UAB vem atuando em apoio ao ensino a distância quando no seu sistema não propõe a criação de uma nova instituição, o que tornaria burocrático e oneroso, mas sim articula com as instituições públicas de 
ensino superiores já existentes no país, para que expanda o ensino superior no país em parcerias com estados e municípios brasileiros.

\subsection{Polos de apoio presencial no ensino a distância}

Os polos de apoio presencial têm na regulamentação do ensino a distância no Brasil a missão de apoiar os cursos da EAD. Por meio do Decreto 5.622, de 19 de novembro de 2005, no art.12, o polo presencial é descrito como "[...] a unidade operacional para o desenvolvimento descentralizado de atividades pedagógicas e administrativas relativas aos cursos e programas ofertados a distância [...]" (BRASIL. Ministério da Educação, 2005).

Assim, os polos presenciais de apoio à EAD passam a ofertar educação superior na modalidade a distância no Brasil, a princípio, com o intuito de formar professores para suprir a demanda da sociedade. Conforme a UAB, "o mantenedor do polo de apoio presencial deverá proporcionar uma infraestrutura física e tecnológica adequada para o pleno desenvolvimento das atividades referentes aos cursos ofertados" (BRASIL, 2013).

Deste modo, para o suporte adequado às atividades pedagógicas e administrativas, os polos devem ter em sua infraestrutura física: salas de aulas, auditórios, laboratórios, secretarias e bibliotecas com recursos informacionais referentes aos cursos e programas ofertados a distância pelas instituições públicas de ensino superior no âmbito do Sistema Universidade Aberta do Brasil.

De acordo com a Coordenação de Aperfeiçoamento de Pessoal de Nível Superior (CAPES, 2013), os polos devem apresentar pelo menos os seguintes recursos humanos: coordenador do polo, tutor presencial, auxiliar para secretaria, técnico de laboratório pedagógico, técnico em informática e o bibliotecário. Uma infraestrutura adequada de um polo se faz necessária para que o aluno da EAD encontre apoio às suas atividades de pesquisa e extensão.

Sobre o programa de expansão, excelência e internacionalização das universidades federais, a Associação Nacional dos Dirigentes de Instituições Federais de Ensino Superior (ANDIFES) destaca a importância que a EAD desempenha no atual cenário educacional, promovendo a democratização do acesso à educação superior, gerando oportunidades a pessoas antes excluídas "[...] jovens e adultos da classe trabalhadora, portadores de deficiência e milhares de professores, [...] possibilitando uma educação continuada de qualidade" (ANDIFES, 2012, p. 9).

A EAD já faz parte de "[...] 52 universidades federais brasileiras atuando em 519 polos implantados. Em 2010, foram 43.959 vagas ofertadas nessa modalidade em 162 cursos de graduação [...]" (ANDIFES, 2012, p. 9).

\section{A UFMG e a educação a distância}


Neste contexto se insere a Universidade Federal de Minas Gerais (UFMG) que oferece cursos de graduação, especialização e extensão na modalidade à distância que estão distribuídos em 24 polos. Os cursos de graduação são Ciências Biológicas, Matemática, Química, Geografia e Pedagogia. Os cursos de especialização são Formação Pedagógica de Educação Profissional na Saúde, Ensino em Artes Visuais, Ensino de Ciências por Investigação, Saúde da Família. Os cursos de extensão em EAD abrangem os cursos de aperfeiçoamento e os cursos de atualização: Educação Ambiental, Educação do Campo, Educação em Direitos Humanos, Educação e Saúde, Educação Integral e Integrada, Produção de Material Didático para a Diversidade. Em 2012, surgiu o I Curso de Aperfeiçoamento em Educação a Distância, ofertado e destinado à formação dos profissionais atuantes nos cursos de graduação, especialização e extensão da UAB/UFMG.

O Centro de Apoio à Educação a Distância (CAED) da UFMG foi criado em 2003 com a finalidade de administrar, coordenar e assessorar o desenvolvimento de cursos de graduação, pós-graduação e extensão na modalidade à distância, bem como produzir estudos e pesquisas sobre EAD e promover a articulação da UFMG com os polos de apoio presencial.

As universidades participantes da UAB possuem Centros de Educação a Distância (CEADs) ou Unidades de Educação à Distância. Estas unidades são estabelecidas como órgãos capazes de apoiar e fazer cumprir o processo de gestão organizacional. No entanto, de acordo com Ribeiro, Timm e Zaro (2007),

[...] as indefinições são muito amplas, principalmente para os CEADs que iniciam suas atividades, [...] precisam identificar suas prioridades, desde a estruturação de polos até a identificação do melhor modelo de negócios para ofertar aos parceiros, passando pela identificação de prioridades na capacitação de todos os atores envolvidos nos processos. Essas e muitas outras questões têm sido resolvidas com base na experiência pessoal dos gestores da EAD, sem que alguma metodologia científica tenha sido empregada para auxiliar nesse sentido (RIBEIRO; TIMM; ZARO, 2007, p. 4).

\section{Biblioteca universitária no apoio a educação a distância}

A UFMG possui em sua estrutura a Biblioteca Universitária (BU) que é o órgão suplementar responsável tecnicamente pelas 25 bibliotecas do Sistema de Bibliotecas (SB) da UFMG e pelo provimento de informações necessárias às atividades de ensino, pesquisa e extensão da universidade, bem como pela coordenação técnica, administração e divulgação dos recursos informacionais (Figura 1 ). 
Figura 1 - Organograma da Biblioteca Universitária - Sistema de Bibliotecas/UFMG

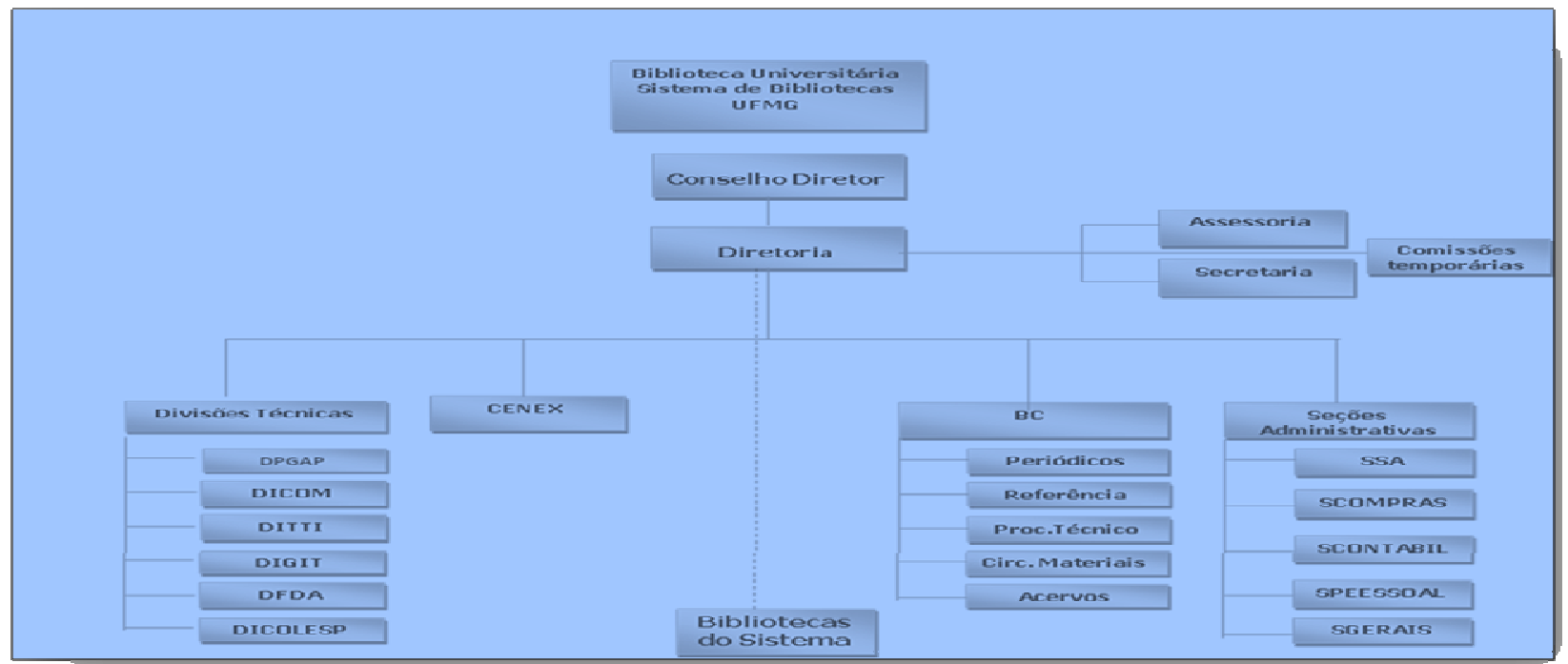

Fonte: UFMG, 2010.

Conforme aponta a Figura 2, esse órgão possui seis divisões técnicas, para suporte as bibliotecas dos cursos presenciais e é responsável pela criação de políticas e diretrizes para as bibliotecas da UFMG. Assim foi criado na sua estrutura um setor de apoio às bibliotecas polo de apoio presencial.

Figura 2 - Organograma das divisões técnicas da Biblioteca Universitária UFMG

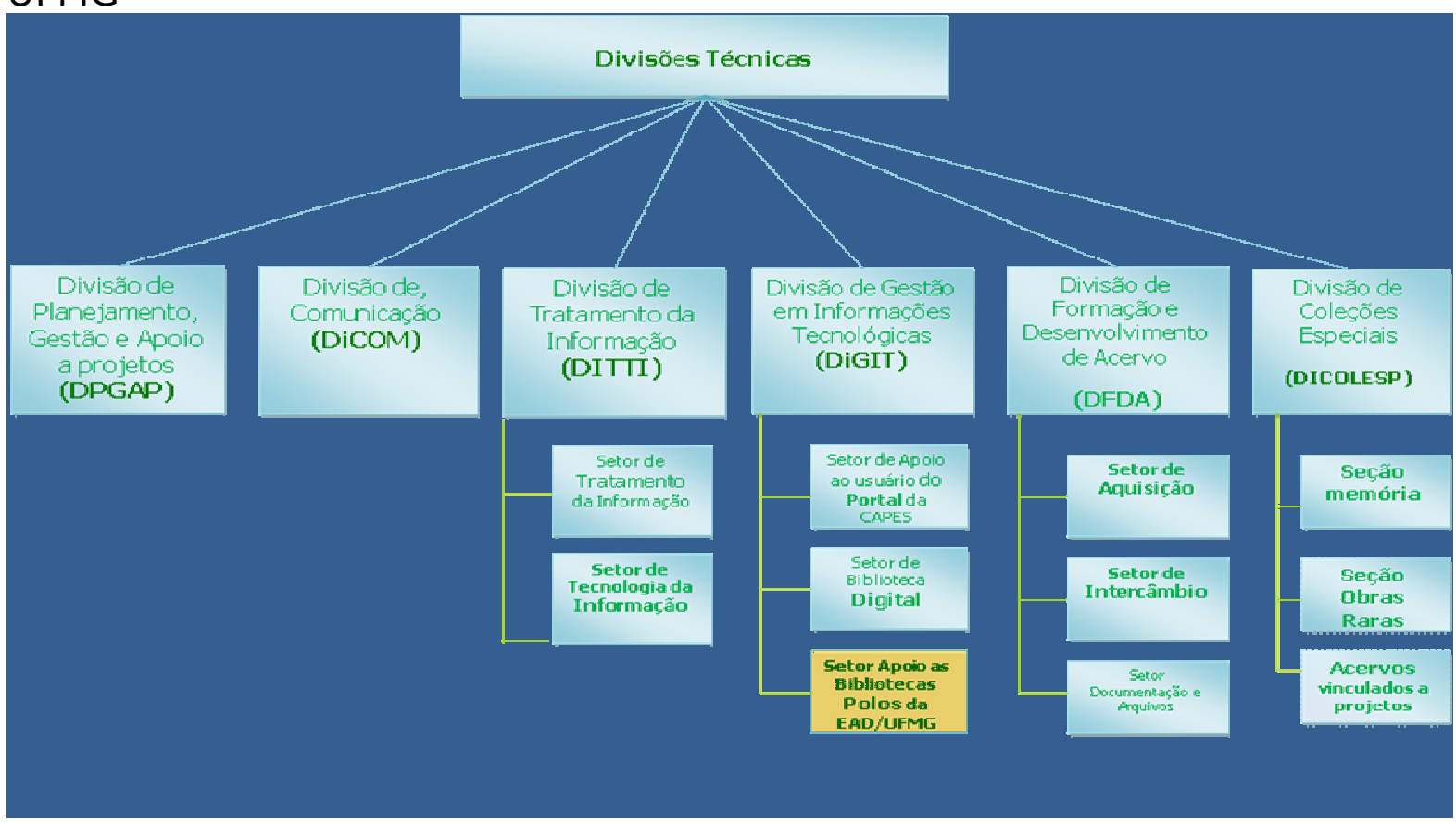

Fonte: UFMG, 2010. 
A BU-SB/UFMG possui e oferece os seguintes serviços aos seus usuários: consulta (local, por telefone, correspondência, fax, e-mail, web); empréstimo do material bibliográfico (domiciliar, entre bibliotecas); levantamento bibliográfico (manual e automatizado); visitas orientadas às bibliotecas do sistema e aos seus acervos raros e especiais; serviço de comutação bibliográfica $\left(\right.$ COMUT $\left.^{2}\right)$; orientação e normalização bibliográfica; treinamento de usuários; alertas, sumários correntes e boletins informativos; exposições, promoção de eventos e ainda biblioteca 24 horas $^{3}$. É também oferecido, sistematicamente, programas de capacitação dos usuários com o objetivo de habilitá-los na utilização das fontes de informação em formato eletrônico disponibilizadas para a comunidade acadêmica da UFMG.

As bibliotecas universitárias procuram analisar as mudanças educacionais e conhecer as inovações da área a fim de aprimorar, adaptar e adequar os seus serviços para prestar um atendimento de qualidade à comunidade acadêmica. Assim, é necessário investir no acesso informacional para os alunos da modalidade à distância. As bibliotecas e os sistemas de bibliotecas precisam estar preparados para receber esse novo usuário e atender as suas necessidades de informação contribuindo com a educação brasileira. Os paradigmas dos serviços prestados na EAD em relação ao acesso a informação técnico-científica precisam ser repensados, principalmente com envolvimento das bibliotecas universitárias ou os sistemas de bibliotecas já existentes no país para que os alunos recebam todo apoio necessário as suas atividades acadêmicas de pesquisa e extensão durante o curso na universidade.

Os alunos que buscam o polo presencial para ter suporte as suas necessidades de ensino e aprendizagem, tais como a pesquisa laboratorial e pesquisa nos acervos que se encontram nos polos; precisam das bibliotecas e consequentemente do profissional bibliotecário. Então, este aluno deverá encontrar a infraestrutura necessária para um atendimento eficiente e eficaz de suas demandas de conhecimento, já que os polos funcionam como extensão da universidade.

O MEC é a instituição que estabelece os critérios para o funcionamento das bibliotecas nos polos presenciais de ensino. Através do documento Referenciais de Qualidade para Educação Superior a Distância os cursos à distância devem ter em sua infraestrutura de apoio uma biblioteca contendo:

[...] um acervo mínimo para possibilitar acesso dos estudantes à bibliografia, além do material instrucional utilizado pelo curso; sistema de empréstimo de livros e periódicos ligados à sede da IES para possibilitar acesso à bibliografia mais

2 COMUT: Permite cópias de documentos técnico-científicos disponíveis nos acervos das bibliotecas brasileiras e em serviços de informação internacionais.

3 A Biblioteca da (Face) e a Biblioteca da (Fale) do SB/UFMG, funcionam em regime 24 horas, a partir das $21 \mathrm{~h} 30$ para os serviços de consulta ao acervo, acesso aos terminais de computadores. Disponível em https://www.bu.ufmg.br/bu/index.php/produtos-e-servicos-2/biblioteca-24-horas. Acesso em 23 de outubro de 2012. 
completa, além do disponibilizado no polo (BRASIL. Ministério da Educação, 2007, p. 19).

Ainda de acordo com o documento em questão, é importante que:

As bibliotecas dos polos devem possuir acervo atualizado, amplo e compatível com as disciplinas ministradas nos cursos ofertados. Seguindo a concepção de amplitude de meios de comunicação e informação da educação à distância, o material oferecido na biblioteca deve ser disponibilizado em diferentes mídias. É importante, também, que a biblioteca esteja informatizada, permitindo que sejam realizadas consultas online, solicitação virtual de empréstimos dos livros, entre outras atividades de pesquisa que facilitem 0 acesso ao conhecimento. Além disso, a biblioteca deve dispor em seu espaço interno de salas de estudos individuais e em grupo (BRASIL. Ministério da Educação, 2007, p. 26).

Desta forma, justifica-se o envolvimento das bibliotecas universitárias e do sistema de bibliotecas, órgãos ou estruturas responsáveis pelas bibliotecas presenciais em empreender essa infraestrutura para apoio técnico-administrativo as bibliotecas polo localizadas em diferentes municípios do estado onde a universidade oferece cursos em EAD.

\subsection{Justificativa}

A pesquisa teve como foco as bibliotecas dos polos de apoio presencial e o acesso aos recursos informacionais disponíveis para os alunos da EAD.

No contexto da educação à distância, progressos e um novo cenário no que tange a área educacional surgem. Deste modo, as Instituições Federais de Ensino Superior (IFES) e seus sistemas de bibliotecas, bibliotecas universitárias e órgãos congêneres precisam se organizar e planejar para oferecer serviços e produtos de alto nível para os alunos dos cursos à distância prestando todo o suporte informacional necessário durante a sua formação.

De acordo com Araújo (2011),

[...] compreender as realidades desses sujeitos, traçando seus perfis a partir das representações que eles fazem da realidade em que vivem, torna-se possível propor soluções para os problemas encontrados no desenvolvimento do sistema educacional brasileiro. [...] com a expansão da educação a distância como opção de formação regular nas instituições de ensino superior públicas por meio do Sistema Universidade aberta do Brasil (UAB), faz-se necessário à realização de estudos que procurem conhecer a realidade informacional e 
cultural de alunos, tutores e professores envolvidos nessa modalidade educacional [...] (ARAÚJO, 2011, p. 29).

Os alunos dos cursos presenciais encontram no SB/UFMG uma estrutura adequada para apoiar as suas atividades de pesquisas tais como: acervo referente às bibliografias básicas dos cursos, coleções online, biblioteca digital de teses e dissertações, portal de periódicos da Capes, material impresso com mais de um milhão de itens entre livros, periódicos, obras raras e especiais, além do atendimento com um profissional especializado, o bibliotecário. Assim, os alunos dos cursos presenciais tem todo este aparato a seu favor.

\subsection{Problema da pesquisa}

Os alunos dos cursos na modalidade a distância nas instituições tem o mesmo atendimento, o mesmo suporte? Assim, diante desse novo cenário da educação à distância surgem às questões a serem tratadas:

a)como a Biblioteca Universitária e/ou Sistema de Bibliotecas poderão apoiar as Bibliotecas Polo nas cidades onde a instituição oferece cursos na modalidade a distância e garantir um atendimento satisfatório? EAD?

b)como proporcionar o apoio e o acesso informacional aos alunos da

c)como assegurar que os alunos da EAD obtenham e utilizem os recursos informacionais necessários às suas atividades de pesquisa?

\subsection{Objetivos}

Diante disso, esta pesquisa aborda a "Educação a Distância, as Bibliotecas Polo e o Acesso aos Recursos Informacionais" que os alunos têm a seu dispor para apoio aos seus trabalhos acadêmico-científicos. 0 Objetivo geral: a) verificar se as bibliotecas polo atendem seus usuários no provimento de informações científicas necessárias às atividades de ensino, pesquisa e extensão; b) fornecer subsídios para melhorar os serviços prestados pelas bibliotecas polo; c) contribuir para elevar o nível da EAD na instituição. Os Objetivos específicos: d) verificar se os alunos da EAD conhecem e/ou examinam o conteúdo informacional do material técnico-científico, se tem acesso; e, se são conhecidos por eles os acervos digitais a que esses alunos têm direito, assim como: a biblioteca digital de teses e dissertações, portal de periódicos da Capes, catálogo web do software Pergamum e outros conteúdos informacionais de acesso livre; e) investigar como os alunos obtêm o apoio informacional às suas atividades de ensino e pesquisa.

\section{Estudo de usuários da EAD}

E assim foi realizado um estudo com os usuários da EAD na UFMG. A natureza da pesquisa é quanti-qualitativa com caráter exploratório. 

qualitativa,

Minayo (2010) diz que compreender é o verbo da pesquisa

[...] compreender relações, valores, atitudes, crenças, hábitos

e representações e a partir desse conjunto de fenômenos humanos gerados socialmente, compreender e interpretar a realidade. $O$ pesquisador que trabalha com estratégias qualitativas atua com a matéria-prima das vivências, das experiências, da cotidianidade e também analisa as estruturas e as instituições, mas entendem-nas como ação humana objetivada. Ou seja, para esses pensadores e pesquisadores, a linguagem, os símbolos, as práticas, as relações e as coisas são inseparáveis (MINAYO, 2010, p. 24).

Em relação ao estudo de usuário na modalidade à distância na UFMG, em um universo de 1222, foram encaminhados questionários a 714 alunos conforme Tabela 1, para diagnosticar as necessidades informacionais e conhecer o comportamento de busca de informação pelo usuários. Para esta pesquisa, no universo total dos alunos, o questionário foi encaminhado para os alunos que estão ligados a cinco polos que foram anteriormente visitados pela pesquisadora.

Tabela 1 - Distribuição de alunos e ex-alunos dos cinco polos de EAD visitados - 2013

\begin{tabular}{c|c|c|c}
\hline Polos da EAD & Alunos & Ex-alunos & $\begin{array}{c}\text { Quantidade total de alunos } \\
\text { e ex-alunos }\end{array}$ \\
\hline \hline Bom Despacho & 76 & - & 76 \\
Buritis & 19 & 50 & 69 \\
Formiga & 123 & 78 & 201 \\
Governador Valadares & 297 & 248 & 545 \\
Montes Claros & 199 & 132 & 331 \\
TOTAL & $\mathbf{7 1 4}$ & $\mathbf{5 0 8}$ & $\mathbf{1 . 2 2 2}$ \\
\hline
\end{tabular}

Fonte: Dados da pesquisa.

As perguntas do questionário foram direcionadas para os problemas e objetivos da pesquisa, ou seja, conhecer como os alunos da EAD têm acesso às fontes de informação, produtos e serviços informacionais para apoiar as suas pesquisas acadêmicas. Dentre os 714 estudantes, 130 alunos responderam o questionário, conforme apresenta a Figura 1. 
Figura 1 - Tela Qualtrics com o quantitativo das respostas

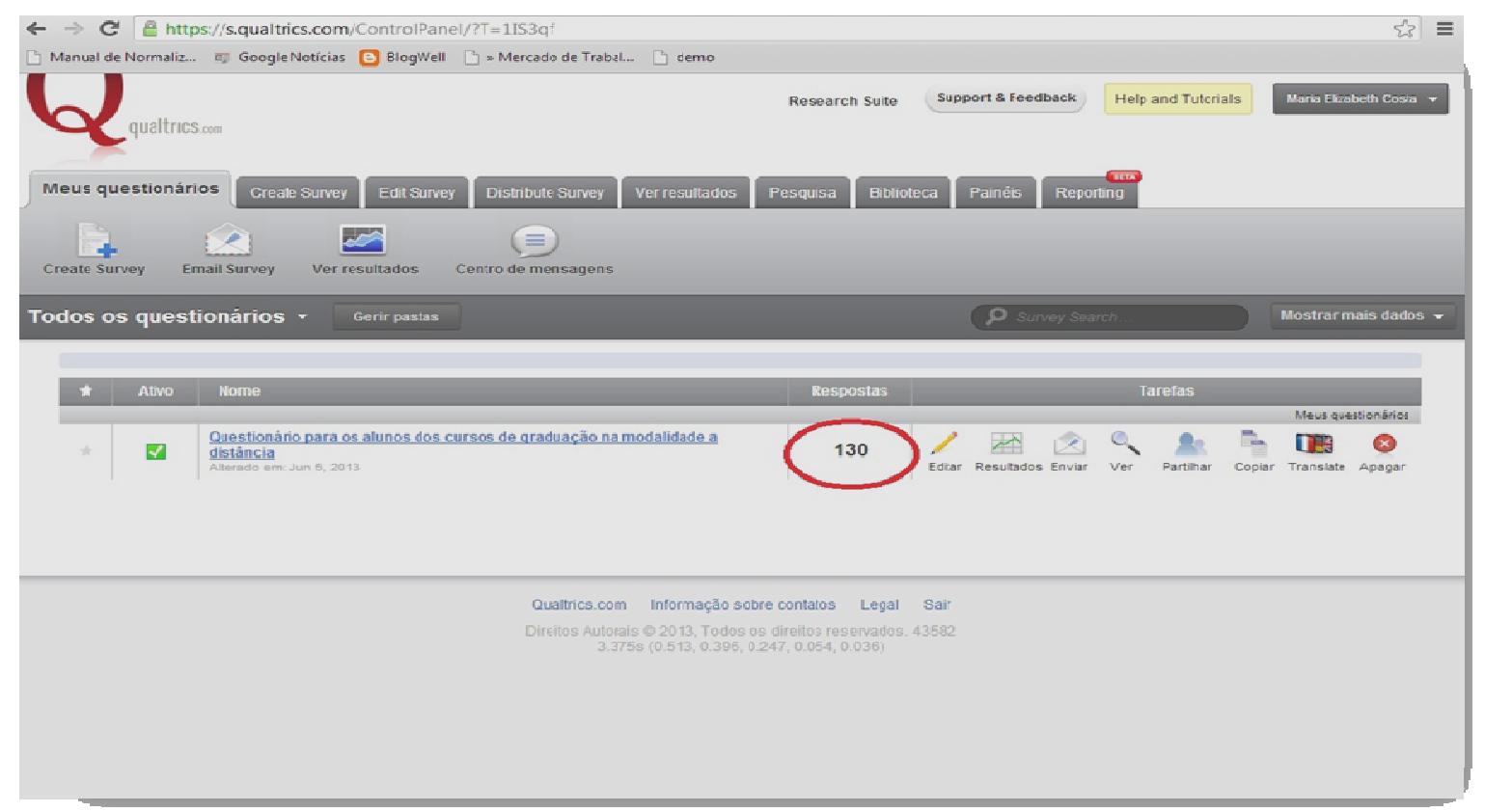

Fonte: Disponível em: <http://www.qualtrics.com>. Acesso em: 25 abr. 2013.

Nesse sentido, Guinchat e Menou (1994) consideram os usuários como um fator essencial [de avaliação] de todo e qualquer sistema de informação. A técnica adotada de coleta de dados com os alunos foi a aplicação de questionários.

De acordo com Araújo (2011),

[...] na educação presencial ou distância, a prática educativa não existe sem os Sujeitos. Então, o projeto de pesquisa volta-se para os usuários de informação da educação a distância. Esses sujeitos culturalmente constituídos que possuem necessidades específicas de informação. Sujeitos que necessitam, buscam e usam a informação para a construção de conhecimentos sob diferentes níveis de apreensão crítica da realidade (ARAÚJO, 2011, p. 24).

Figueiredo (1994) define estudo de usuários como:

Investigações que fazem para saber o que os indivíduos precisam em matéria de informação, ou então, para saber se as necessidades de informação por parte dos usuários da biblioteca ou de um centro de informação estão sendo satisfeitas de maneira adequada (FIGUEIREDO, 1994, p. 7).

Neste contexto, a pesquisa realizada é social, e pode caracterizá-la como estudos exploratórios e descritivos. Uma pesquisa pode ser considerada de natureza exploratória, quando requer levantamento 
bibliográfico, entrevistas com pessoas que tiveram experiências práticas com o que (se) esteja pesquisando e análise de exemplos que estimulem a compreensão.

Essa pesquisa além de ser acadêmica é também uma pesquisa profissional no sentido de verificar como a Biblioteca Universitária, enquanto responsável pelo provimento de informações necessárias às atividades de ensino, pesquisa e extensão da universidade, bem como pela coordenação técnica, administração e divulgação dos recursos informacionais, pode atuar para o fornecimento de apoio às bibliotecas dos polos e atender 0 aluno da EAD no suporte aos recursos informacionais necessários as suas atividades de pesquisa e extensão.

\section{Análise dos resultados}

Os polos com maior número de alunos são os dos municípios de Araçuaí com 544 alunos e Governador Valadares com 545 alunos, enquanto Uberaba e Januária são os polos que possuem menor quantidade de alunos com 46 e 35, respectivamente, o equivalente a apenas $2 \%$ somando o percentual dos dois polos (Gráfico 1 ).

Gráfico 1 - Distribuição geral de alunos por Polo (porcentagem) - 2013
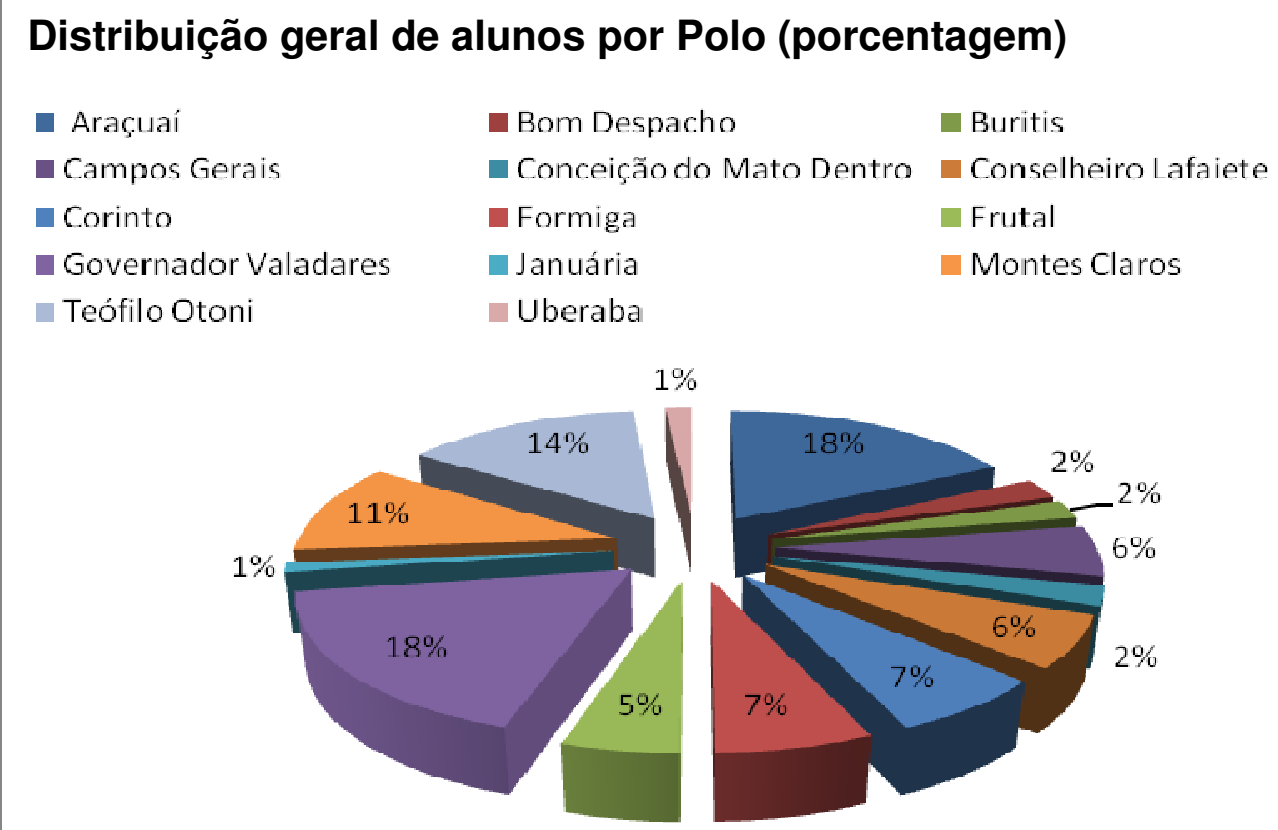

Fonte: Dados da pesquisa.

\subsection{Perfil do usuário na modalidade de ensino a distância}

Pode-se notar, conforme Tabela 2, que 39\% dos alunos estão entre 31 a 40 anos e corresponde a maior parcela da faixa etária. Em seguida, 
com $22 \%$ estão os alunos acima de 40 anos e $15 \%$ na faixa de 26 e 30 anos.

Tabela 2 - Distribuição de alunos por faixa etária - 2013

\begin{tabular}{l|c|c|c}
\hline \multicolumn{1}{c|}{ Faixa etária } & & $\begin{array}{c}\text { Valores } \\
\text { Absolutos }\end{array}$ & $\%$ \\
\hline \hline Até 20 anos & & 8 & $6 \%$ \\
\hline 21 a 25 anos & & 23 & $18 \%$ \\
\hline 26 a 30 anos & & 20 & $15 \%$ \\
\hline 31 a 40 anos & & 51 & $39 \%$ \\
\hline Acima de 40 anos & & 28 & $22 \%$ \\
\hline Total & & 130 & $100 \%$ \\
\hline
\end{tabular}

Fonte: Dados da pesquisa.

De acordo com os resultados obtidos, pode se concluir que as pessoas que buscam o ensino na modalidade à distância estão em uma faixa etária de maior amadurecimento. Alguns estudos como os de Ferreira, Mendonça e Mendonça (2007, p. 7) comprovam esta realidade, pois "são profissionais que estão em plena capacidade produtiva e optam pela EAD para aumentarem seus conhecimentos [...]." Ainda segundo outras pesquisas, o aluno online 'típico' é geralmente descrito como alguém que tem mais de 25 anos de idade, sendo esta uma característica encontrada também nos dados coletados; sendo as mulheres que mais se destacam na busca pela educação à distância. Conforme afirmam Ferreira, Mendonça e Mendonça (2007), as pessoas optam pelas comodidades oferecidas por um curso a distância, pois fazem o acesso de suas casas obedecendo as suas agendas individuais em relação a horário e tempo de estudo.

\subsection{Uso da Biblioteca e não uso}

Observa-se que $57 \%$ dos alunos usam as bibliotecas dos polos de apoio para as atividades de pesquisa. Dentre os respondentes que utilizam a biblioteca, pode-se inferir que o polo da cidade de Governador Valadares é o que possui o maior número de alunos e consequentemente o maior percentual de estudantes que fazem uso da biblioteca do polo. Os que alegam não utilizar a biblioteca o motivo é o número reduzido de itens no acervo para a demanda e ainda foi mencionado a distância entre a biblioteca do polo e a residência dos graduandos.

\subsection{Uso das fontes de informação}

Dentre as fontes de informação (apostilas, livros-textos, artigos científicos, monografias, dissertações, teses, legislações, normas técnicas, patentes, sites de instituições de pesquisa) mais recomendadas pelos professores e tutores da EAD, as apostilas do curso são as que tiveram 
um maior percentual das respostas (50\%), seguido dos livros-textos com $36,51 \%$, os artigos científicos com $20,33 \%$ e os textos extraídos dos sites de pesquisa com 23,20\%. As normas técnicas, as teses, dissertações e monografias, as legislações e por último as patentes foram consideradas como as menos recomendadas.

Em relação à tipologia das fontes de informação, 67\% dos respondentes preferem ambos os suportes (digital e impresso), como mostra o Gráfico 2. Pode-se afirmar ainda que apenas $9 \%$ dos alunos preferem somente as fontes eletrônicas e $23 \%$ preferem as fontes impressas.

Gráfico 2 - Tipologia das fontes de informação

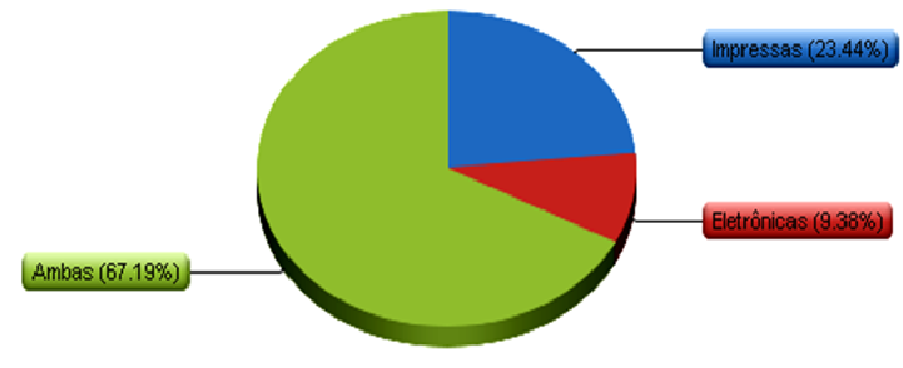

Fonte: Dados da pesquisa.

Sobre a frequência de uso das fontes informacionais para a realização de trabalhos e estudos acadêmicos pelos alunos os resultados mostraram que as apostilas são as fontes mais utilizadas para este fim com $71,32 \%$. Em seguida os livros-texto com uma frequência diária de $54,76 \%$ e os textos extraídos de sites de instituições de pesquisa com $52,18 \%$. A frequência de uso dos artigos científicos teve alto grau de variação, contudo, esta fonte é utilizada diariamente por 23,53\% dos alunos. Nota-se que as patentes não são conhecidas pela maioria dos respondentes com $64,60 \%$. As monografias, dissertações, as teses, as legislações e as normas técnicas são utilizadas pelo menos uma vez por mês pela maior parte dos alunos. Por meio da pesquisa também fica evidente que essas mesmas fontes não são conhecidas para 73,39\% dos alunos.

No que se refere ao grau de necessidade das fontes informacionais para a realização de trabalhos acadêmicos ficou definida que as apostilas do curso com $82,03 \%$ e os livros-texto com $79,69 \%$ como os recursos de informação mais relevantes durante a graduação. Em seguida, os textos extraídos de sites de instituições de pesquisa com 50,41\% e os artigos científicos com 37,40\%. As normas técnicas, as monografias, dissertações e teses e as legislações tiveram a porcentagem de $42,37 \%, 37,40 \%$ e $33,61 \%$, respectivamente. 
Através da análise dos resultados, constatou-se que as fontes informacionais com maior grau de confiança para os estudos e trabalhos acadêmicos são as apostilas dos cursos e os livros-texto com $64,57 \%$ e $57,26 \%$, respectivamente. Em seguida, os artigos científicos com $41,46 \%$, as normas técnicas $42,15 \%$, as legislações $37,50 \%$ e as patentes $16,52 \%$.

Os textos extraídos de sites de instituições de pesquisa obtiveram somente $30,65 \%$ de confiabilidade por parte dos alunos, em contrapartida à opção "confio pouco" teve alto percentual ficando com $21,77 \%$. Na resposta "confio", destacaram-se as teses, dissertações e monografias no grau de confiabilidade.

\subsection{Uso dos produtos e serviços oferecidos pelas bibliotecas}

O grau de conhecimento sobre serviços e produtos informacionais oferecidos (ou que podem vir a ser oferecidos) nas bibliotecas também foi analisado pela pesquisa. Por intermédio dela, examinou-se o acervo, as bases de dados, a biblioteca digital de teses e dissertações, o catálogo online da base do acervo, o serviço de comutação bibliográfica - e o portal de periódicos da Capes. Apenas $9 \%$ dos estudantes conhecem os demais produtos disponibilizados para fins acadêmico-científicos. Pode-se inferir por meio desta questão, que a maioria dos alunos da EAD da UFMG desconhece ou conhecem pouco os serviços informacionais digitais ofertados para as bibliotecas presenciais e que podem ser oferecidos nas bibliotecas dos polos.

O produto informacional mais utilizado para elaboração de estudos e trabalhos acadêmicos pelos alunos da EAD da UFMG é a Internet com $76 \%$, sendo que a maioria a utiliza diariamente. Porém percebe-se que as bases de dados, o portal de periódicos da Capes e a biblioteca digital de teses e dissertações e o catálogo online da biblioteca e o serviço de comutação bibliográfica são subutilizados pelos alunos da modalidade à distância.

Grande parte dos respondentes ao serem perguntando informa o alto grau de interesse em participar de treinamentos e receber orientações sobre os serviços informacionais oferecidos pela biblioteca. Esta afirmativa está em acordo com as respostas à questão que investiga acerca da frequência de utilização das fontes de informação ter um percentual baixo, pois a baixa frequência se deve ao fato do desconhecimento de como utilizá-las. Na questão acerca das fontes informacionais consideradas mais confiáveis e na pergunta sobre o grau de conhecimento sobre os serviços e produtos informacionais oferecidos pelas bibliotecas, esses produtos foram considerados também desconhecidos pelos alunos da EAD.

Cabe destacar também que houve grande interesse por parte da maioria dos alunos em contribuir com a pesquisa. Alguns comentaram sobre a relevância do estudo para a universidade e outros sobre a precariedade dos produtos e serviços prestados nas bibliotecas dos polos. 
A partir dessas análises, faz-se necessário que as bibliotecas da IES, responsáveis pelos cursos do ensino a distância, divulguem e ofereçam treinamentos desses produtos e serviços para os alunos dos cursos dessa modalidade possibilitando um maior conhecimento das diversas fontes de informação e consequentemente um maior uso tornando-os usuários reais da biblioteca e dos serviços informacionais oferecidos pelas Bibliotecas Universitárias ou pelos Sistemas de Bibliotecas das IES.

Dessa forma, faz-se necessário também equipar as bibliotecas dos polos, principalmente com coleções vastas e variadas e, principalmente, com o acervo solicitado na bibliografia básica dos cursos, além de orientação e treinamento de como utilizar os produtos e serviços informacionais online já existentes, buscando uma melhor usabilidade de seus recursos de informação por parte do consulente.

\section{Considerações finais e recomendações}

Por atuar em Sistema de Bibliotecas, a pesquisadora já havia sentido a necessidade de uma interação entre o Ensino a Distância e as Bibliotecas Universitárias; o subsídio destas às bibliotecas dos polos de apoio presencial dos cursos à distância e consequentemente aos usuários dessa modalidade educacional. Uma interação necessária das áreas: a educação à distância, a biblioteconomia e a ciência da informação.

A pesquisadora enquanto sua atuação no Sistema de Biblioteca idealizou e após aprovação no órgão colegiado, criou-se na Biblioteca Universitária, órgão gerenciador das 25 Bibliotecas do Sistema, um Setor de Apoio as Bibliotecas Polo da EAD, visando o apoio aos recursos informacionais para os alunos dessa modalidade de ensino na instituição e direciona a pesquisa para Educação a Distância e as Bibliotecas Polo de Apoio Presencial. E assim busca transformar a teoria à prática e a prática em ação, e faz da pesquisa, além de outras características em uma pesquisa-ação.

Assim, dentro da perspectiva da pesquisa-ação que de acordo com Trip (2005) "visa melhorar a prática" algumas diretrizes advindas dos resultados da pesquisa vêm sendo apoiadas, construídas e implementadas pelos órgãos ${ }^{4}$ e setores ${ }^{5}$ da instituição pesquisada, objetivando atender 0 usuário da modalidade a distância referente aos recursos informacionais. Dentre elas podem ser citadas um tutorial para os alunos da EAD sobre "como acessar a base de acervos bibliográficos"i" (livros, periódicos e outros) através do Software Pergamun. Um segundo tutorial de "como acessar o portal de periódicos da Capes para a pesquisa acadêmica" planejado para os alunos da EAD, está em construção na Instituição. E ainda uma proposta de construção de uma biblioteca virtual de acesso livre para os alunos da EAD.

\footnotetext{
${ }^{4}$ Biblioteca Universitária (BU/UFMG) e o Centro de Apoio a Educação a Distância (CAED/UFMG).

${ }^{5}$ BU-Setor de Apoio as Bibliotecas Polos da EAD e Setor de Apoio ao Usuário do Portal da Capes na UFMG.

${ }^{6}$ Criado pelos Setores da BU com apoio do CAED-Instalado no sitio da BU. Disponível em: <www.bu.ufmg.br>. Acesso em: 27 mar. 2013.

${ }^{7}$ Em construção.
} 
Em relação às bibliotecas universitárias das IES estas precisam buscar solução na criação de diretrizes e contribuir com as bibliotecas dos polos e automaticamente com a educação à distância no país. As bibliotecas acadêmicas devem se adaptar aos novos tempos para irem ao encontro das necessidades dos usuários atuais sendo eles: "usuário presencial, ou remoto".

Na nova era a sociedade da informação traz mudanças e desafios que perpassam todas as perspectivas e formas de buscar o conhecimento, desde a aquisição e processamento até a disseminação da informação. A EAD na sua forma epistemológica ${ }^{8}$, assimétrica e empírica busca seu apogeu no país tendo em vista fazer com que os cidadãos tenham acesso a informação e ao conhecimento.

\section{Referências}

ARAÚJO, S. S. S. de. Cultura informacional, representações sociais e educação a distância: um estudo de caso da EAD na UFMG. 2011. 235f. Dissertação (Mestrado em Ciência da Informação) - Escola de Ciência da Informação, Universidade Federal de Minas Gerais, Belo Horizonte, 2011.

ASSOCIAÇÃO NACIONAL DOS DIRIGENTES DE INSTITUIÇÕES FEDERAIS DE ENSINO SUPERIOR (ANDIFES). Programa de expansão, excelência e internacionalização das universidades federais. Brasília, 2012. Disponível em:

$<$ http://www.andifes.org.br/wpcontent/files flutter/1360930928PEEXIU.pdf>. Acesso em: 7 out. 2012.

BRASIL. Blog do Planalto. Brasília, 2011. Disponível em: $<$ http://blog.planalto.gov.br/assunto/escolas-tecnicas/>. Acesso em: 23 nov. 2012.

BRASIL. Ministério da Educação. Lei n. 9.394 de 20 de dezembro de 1996. Estabelece as diretrizes e bases da educação nacional. Diário Oficial da União, Brasília, $1996 . \quad$ Disponível em: <http://portal.mec.gov.br/seed/arquivos/pdf/tvescola/leis/lein9394.pdf>. Acesso em: 06 jul. 2012.

BRASIL. Ministério da Educação. Decreto n. 5.622 de 19 de dezembro de 2005. Regulamenta o Art. 80 da Lei no 9.394, de 20 de dezembro de 1996, que estabelece as diretrizes e bases da educação nacional. Diário Oficial da União, Brasília, DF, 20 dez. 2005. Disponível em: <http://portal.mec.gov.br/sesu/arquivos/pdf/portarias/dec5.622.pdf> . Acesso em: 10 set. 2012.

BRASIL. Ministério da Educação. Instituto Nacional de Estudos e Pesquisas Educacionais Anísio Teixeira (INEP). 2011. p. 8. Disponível em: $<$ http://download.inep.gov.br/acoes internacionais/estatisticas educacion ais/ocde/education at a glance/eag 2011 resumo tecnico brasil.pdf? $>$. Acesso em: 22 mai. 2015.

\footnotetext{
${ }^{8}$ A epistemologia estuda a origem, a estrutura, os métodos e a validade do conhecimento, motivo pelo qual também é conhecida como teoria do conhecimento.
} 
BRASIL. Ministério da Educação. Instituto Nacional de Estudos e Pesquisas Educacionais Anísio Teixeira (INEP). 2012. Disponível e <http://portal.inep.gov.br/>. Acesso em: 13 de out. 2012.

BRASIL. Ministério da Educação. Secretaria de Educação a Distância. Referenciais de qualidade para educação superior a distância. Brasília. 2007. em: < http://portal.mec.gov.br/seed/arquivos/pdf/legislacao/refEAD1.pdf>. Acesso em: 12 abr. 2012.

BRASIL. Universidade Aberta do Brasil. 2013. Disponível em: $<$ http://www.uab.capes.gov.br/index.php/polos841937/mantenedor>.Acesso em: 07 abr. 2012.

COORDENAÇÃO DE APERFEIÇOAMENTO DE PESSOAL DE NÍVEL SUPERIOR (CAPES). Institucional: missão e objetivos. 2013. Disponível em: $<$ https://www.periodicos.capes.gov.br/?option=com pcontent\&view=pcon tent\&alias $=$ missao-objetivos $\& m n=69 \& s m n=74>$. Acesso em: 24 mar. 2013.

COSTA, M. E. de O. Educação a distância, bibliotecas polo e o acesso informacional: um estudo de caso. 2013. 192f. Dissertação (Mestrado em Tecnologia e Gestão em EaD) - Universidade Federal Rural de Pernambuco, Recife, 2013.

FERREIRA, Z. N.; MENDONÇA, G. A. de A.; MENDONÇA, A. F. de. O perfil do aluno de educação a distância no ambiente teleduc.In:CONGRESSO INTERNACIONAL DE EDUCAÇÃO A DISTÂNCIA, 13., 2007, Curitiba. Anais... Curitiba: [CIETEP], 2007.

FIGUEIREDO, N. M. Estudos de uso e usuários da informação. Brasília: IBICT, 1994.

GUINCHAT, C.; MENOU, M. Usuários. In: GUINCHAT, C.; MENOU, M. Introdução geral às técnicas da informação e da documentação. Brasília: IBICT, 1994. p. 481-491.

LITTO, F. M. O. Retrato frente e verso da aprendizagem a distância no Brasil. ETD: Educação Temática Digital, Campinas, v. 10, n. 2, p. 108122, jun. 2009

MINAYO, M. C. S. O desafio do conhecimento.12a ed. São Paulo: Editora Hucitec; 2010.

QUALTRICS LABS INC: software livre. Versão 12.018. EUA: Provo UT, 2013. Disponível em: < http://www.qualtrics.com/>. Acesso em: 25 abr. 2013.

NASCIMENTO, M. I. M. Biografia de Darcy Ribeiro. 2001. Disponível em:

<http://www.histedbr.fe.unicamp.br/navegando/glossario/verb b darcy $r$ ibeiro.htm >. Acesso em: 23 mai.2015.

RIBEIRO, L. O. M.; TIMM, M. I.; ZARO, M. A. Gestão de EAD: a importância da visão sistêmica e da estruturação dos CEADs para a 
escolha de modelos adequados. RENOTE - Revista Novas Tecnologias na Educação. Porto Alegre, v. 5, n. 1, jul. 2007. Disponível em: <http://seer.ufrgs.br/renote/article/view/14316>. Acesso em: $10 \mathrm{fev}$. 2013.

TRIP, D. Pesquisa-ação: uma introdução metodológica. Educação e Pesquisa, São Paulo, v. 31, n. 3, p. 443-466, set./dez. 2005.

UNIVERSIDADE FEDERAL DE MINAS GERAIS (UFMG). Biblioteca Universitária. 2013. Disponível em: <https://www.bu.ufmg.br >. Acesso em: 23 out. 2012.

UNIVERSIDADE FEDERAL DE MINAS GERAIS (UFMG). Centro de Apoio à Educação a Distância - CAED. 2012. Disponível em: <https://www.ufmg.br/EAD/site/>. Acesso em: 11 abr. 2012. 